\title{
LA PAIDEIA ISOCRÁTICA Y LAS NUEVAS TECNOLOGÍAS: FIN Y MEDIOS DE LA ENSEÑANZA DEL DERECHO EN EL ESPACIO EUROPEO DE ENSEÑANZA SUPERIOR BAJO el Plan de Bolonia

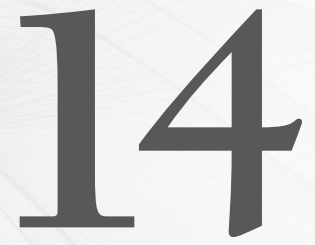

Isocratic paideia and new technologies: end and means of legal education in the european higher education Plan under the Bologna

\section{Francisco de la Torre Olid}

Catedrático de Derecho Civil. Director del Dpto. de C.C. S.S. Jurídicas y de la Empresa. Director de la Escuela de Práctica Jurídica. Universidad Católica de Murcia.

\section{Pilar Conde Colmenero}

Licenciada en Filosofía. Profa. Dra. de Derecho del Trabajo y de la Seguridad Social. Universidad Católica de Murcia.

\section{Maria Mendez Rocasolano}

Profa. Dra. de Derecho Constitucional. Universidad Católica de Murcia.

Recebido em: 29.07.2012

Aprovado em: 02.09.2012

ÁREA Do DIREITO: Educação; Internacional

RESUMEN: Las siguientes reflexiones son fruto del diálogo de sus autores que examinan propuestas e iniciativas pedagógicas mediante criterios metodológicos innovadores que despiertan la iniciativa, el sentido crítico y la creatividad en
ABSTRACT: The following reflections are the result of the dialogue of the authors who examine proposals and teaching initiatives through innovative methodological criteria that arouse the initiative, critical thinking and creativity in 
los estudios de grado y post grado en derecho dentro del espacio común de educación superior, bajo el marco del Ilamado Plan Bolonia. Pretende lograrse el objetivo en España, dentro del contexto europeo de que las universidades sean centros de promoción y afianzamiento de la cohesión social, de promoción de la igualdad para lograr sociedades democráticas avanzadas con la premisa de elevar el nivel del conocimiento, las destrezas y competencias de los ciudadanos. Especialmente los estudios de grado y postgrado en derecho cobran protagonismo en esta labor y así se propone la exportación de una nueva asignatura que con la cultura y la dignidad de la persona como referente forme a los individuos para ser ciudadanos responsables y participativos en los sistemas políticos complejos de nuestros dias. Además, para cumplir con el reto de incorporar las nuevas tecnologias de la comunicación y de la información a la docencia y a la investigación jurídica se proponen iniciativas creativas e innovadoras que van desde la docencia online, a la creación de un Parlamento virtual o la explicación del derecho a través de imágenes.

Palabras clave: Poder - Nuevas tecnologías de la comunicación y de la información (TICS) - Estudios online - Igualdad - Acceso universal - Democracia - Derecho. undergraduate and graduate degree in law at the Common Space of Higher Education under the framework of Plan Bologna. Aims achieved the goal in Spain, in the European context that universities are centers for the promotion and strengthening of social cohesion, equality promotion to achieve advanced democratic societies with the premise of raising the level of knowledge, skills and competencies of citizens. Especially the undergraduate and postgraduate law take center stage in this work and so proposed export of a new subject that culture and dignity as individuals form reference for responsible citizenship and participatory political systems complex today. In addition, to meet the challenge of incorporating new technologies of communication and information for teaching and legal research proposes creative and innovative initiatives ranging from online teaching, the creation of a virtual or explanation Parliament law through images.

KeYwords: Power - New technologies of communication and information (TICS) - Online studies - Gender - Universal access - Democracy - Law.

Sumario: I. Introducción - II. La paideia isocratica o la formación de la ciudadanía como finalidad universal y universitaria - III. La aplicación de las nuevas tecnologias a las enseñanzas jurídicas de grado y postgrado en el marco del Plan de Bolonia - IV. Propuestas concretas de utilización de las nuevas tecnologias en la docencia e investigación jurídica en el espacio europeo de educación superior: 1. Participación de la Administración Pública: el derecho en la red y el manejo de bases de datos jurídicas; 2 . Derecho online; 3 . Derecho en imágenes - V. Conclusiones - VI. Bibliografia.

\section{INTRODUCCIÓN}

En Europa se ha creado un espacio común de educación superior bajo el marco del llamado Plan Bolonia con la intención que sean las universidades centros de promoción y afianzamiento de la cohesión social, de reducción de las desigualdades con la premisa de elevar el nivel del conocimiento, las destrezas y competencias de los ciudadanos. Desde las instituciones europeas se pretende 
que las políticas de educación superior dediquen sus esfuerzos a maximizar el potencial de las personas en cuanto a su desarrollo personal y participen como sujetos responsables en el desarrollo de una sociedad sostenible, democrática y basada en el conocimiento.

El Espacio Europeo de Educación Superior (EEES) actualiza la universidad, que desde sus primeras manifestaciones como cathedra en la Europa del siglo IX ha pretendido divulgar, expandir y transmitir el conocimiento en sentido amplio. Normalmente ha sido fiel señora al servicio de la cultura y el poder, pero también en sus aulas se han gestado los caracteres y personalidades de grandes reformistas y revolucionarios, así bajo el Plan Bolonia, la esencia europea se manifiesta, brindando a todos, una Universidad abierta y conectada con la sociedad dentro de un modelo de convivencia basado en la igualdad efectiva de oportunidades, que tiene uno de sus pilares más sólidos en la formación universitaria. ${ }^{1}$

Reconocido el protagonismo que la universidad tiene en el desarrollo de la cultura y de la sociedad, a continuación, abrimos al lector el diálogo sobre la finalidad y los medios para alcanzar dicho objetivo desde la enseñanza del derecho, entre los Profesores Francisco de la Torre Olid, Pilar Conde Colmenero y María Méndez Rocasolano. Nuestras reflexiones se basan en una extensa experiencia en la docencia y en la investigación jurídica en diversas instituciones públicas y privadas dentro del panorama español e internacional, en el conocimiento de las entrañas de las instituciones universitarias desde cargos académicos de responsabilidad de primer orden, representado este último por el Prof. de la Torre, desde la visión amplia, finalista y objetiva del conocimiento de la ciencia filosófica por parte de la Profa. Conde y desde la experiencia multicultural y de la ciencia política, de la Profa. M. Rocasolano. Representamos aquí la básica división de derecho privado y público con la visión propia del derecho civil, al que está adscrita la línea de investigación del Prof. de la Torre, el derecho laboral en el que se centran los estudios de la Profa. Conde y el derecho constitucional donde se encuentran ubicadas las reflexiones de las Profa. M. Rocasolano.

Es una honra participar en el Conselho Nacional de Pesquisa em Direito Conpedi, para proponer mejoras en la calidad de la enseñanza y la investigación del derecho y la educación jurídica en Brasil, pues ese reto es también nuestra preocupación en España.

Somos conscientes del reto que plantea el marco de Bolonia en el desarrollo de los estudios jurídicos de grado y postgrado, el notable esfuerzo que supone

1. Así lo expresa el Comunicado de Londres, refiriéndose a la "dimensión social" del proceso de Bolonia. 
en materias tan rígidas como las legales facilitar servicios adecuados a los estudiantes, crear itinerarios de aprendizaje flexibles tanto de acceso como de recorrido dentro de la educación superior, ampliar la participación a todos los niveles sobre la base de igualdad de oportunidades y además revisar la interpretación de las materias jurídicas para superar el tradicional atributo de instrumento del poder que el derecho representa.

Sin evadir la notable responsabilidad que el profesor universitario tiene en el marco social, y a la vista de las desigualdades provenientes del desconocimiento del sistema sociopolítico que limita la libertad y la participación de los ciudadanos, proponemos una reflexión que bajo los parámetros de un derecho justo y la dignidad de la persona impulse, con las nuevas tecnologías y la cultura como herramientas, la formación de juristas que colaboren activamente en la conformación de una verdadera sociedad igual y democrática.

\section{LA PAIDEIA ISOCRATICA O LA FORMACIÓN DE LA CIUDADANÍA COMO FINALIDAD UNIVERSAL Y UNIVERSITARIA}

Internet en el siglo XXI y la paideia isocrática del siglo V antes de Cristo se alían dando pautas creativas para el desarrollo de los estudios de derecho en nuestros días. Tras haber impartido clases de diversas materias jurídicas en distintas instituciones coincidimos en localizar un gran problema social que se cierne sobre los sistemas educativos actuales. Mientras que los alumnos de derecho, política, historia y filosofía son formados como ciudadanos, recibiendo nociones de cuáles son sus derechos y obligaciones, cuáles son las instituciones básicas del Estado y cómo y porqué se organiza el sistema social a través de la Constitución, los demás no reciben ninguna explicación sobre asuntos tan relevantes. Nos encontramos así con una gran masa de profesionales, médicos, arquitectos o ingenieros que no saben a ciencia cierta qué derechos tienen constitucionalmente garantizados, qué tipos de leyes rigen sus vidas o que existe una figura el defensor del pueblo y unos derechos fundamentales que les asisten. Nada que decir de aquellos que no tienen la oportunidad de cursar estudios superiores... Esta realidad supone una desigualdad en lo que a participación en la vida pública se refiere, que divide bochornosa e injustamente al pueblo de un Estado en lo que podríamos denominar individuos con conocimientos y ciudadanos educados políticamente. Esta idea es la que se encuentra en la base de la gobernanza y en su desarrollo, la responsabilidad social universitaria aparece en el marco de la estrategia universitaria para el 2015 como tercera 
misión del Espacio Europeo de Educación superior. ${ }^{2}$ Esta idea es la misma que inspiró en el año 400 a.C. a Isocrates en la fundación de una escuela de retórica, que buscaba la formación integral de la persona educando a los miembros de la comunidad para engrandecer a la civitas por excelencia través de la cultura. ${ }^{3}$

Isócrates proponía la educación política de los ciudadanos como camino para establecer un cambio político que dependiese de un acercamiento a la virtud, lo que hemos llamado derecho justo, ${ }^{4}$ así el filosofo además de ocuparse de la dimensión exterior de Atenas como uno de los representantes del panhelenismo, dedicó su vida y obra a plantear soluciones a los problemas de corrupción de la democracia ateniense. De plena actualidad, sus planteamientos nos sirven para arrojar algo de luz sobre el problema que estamos afrontando.

Tras las guerras médicas el territorio griego quedó sumido en interminables guerras por el poder, cuyas consecuencias negativas movieron a los dirigentes

2. La Estrategia 2015 contempla la aprobación de un eje central de trabajo dedicado a la responsabilidad social universitaria, diseñado en estrecho contacto con las propias universidades y con las principales partes interesadas en esta materia. Por ello, un objetivo claro de la EU 2015 es que en su horizonte temporal todas las universidades tengan un proyecto de RSU aprobado por el Consejo de Gobierno y Consejo Social y que sea difundido y conocido en el ámbito de su comunidad universitaria.

3. Isocrates nació en 436 en Atenas antes de las Guerras del Peloponeso y murió después que Grecia perdiera su independencia frente a Macedonia en el 338 a.C. Procedente de una familia pudiente, tuvo como maestros a Sócrates y Platón, y siguió las enseñanzas de Gorgias. Fue director de un escuela de retórica en Chíos durante el periodo del reinado de los Treinta Tiranos de Atenas, más tarde creó su propia escuela que contó como discípulos a los historiadores Éforo y Theopompo, destacan también Isaeus, Licurgo, Hypereides, y Nicocles que gobernó Salamina. Sus obras principales son ensayos y textos sobre oratoria, la temática tratada principalmente es la política del momento, se preocupa del contenido moral lo que le diferencia de sus colegas los retóricos. Se conservan 21 discursos y 9 cartas. Las cartas tratan distintos temas que van desde las advertencias dirigidas a los déspotas y el llamamiento a los líderes educación, hasta el arte o la belleza pasando por la retórica. Destacan "contra los sofistas" (391-390 a.C.), "Elogio a Helena" (370 a.C.), "Arquidamo" (366 a.C.), "Antídosis" (353 a.C.) y "Panatenaico". De los discursos cabe especial mención el "Areopagítico" y "Sobre la paz" (355 a.C.) se ocupan de la política ateniense y el ocaso de la democracia griega.

4. En este sentido comenta: "Conviene que quienes gobiernen con rectitud no llenen los pórticos con escritos, sino que graben la justicia en las almas: porque no es con decretos sino con buenas costumbres como se gobiernan las ciudades. Aquellos que han recibido una educación perversa osarán transgredir aun las leyes más puntillosamente redactadas, en tanto que los que han sido bien educados querrán obedecer aquellas establecidas con sencillez". Isócrates. Pantenaico, p. 49-50. 
de los Estados griegos a procurar vías y encontrar soluciones a una crisis que se fraguaba sobre la corrupción política, la decadencia ética y moral y la ambición por el poder y ahí es donde Isócrates plantea el desarrollo de la función política de la educación como vía para superar la crisis sociopolítica de su época, la paideia, concebida como educación y cultura. ${ }^{5}$

Igual que entonces, nuevamente las sociedades abatidas por la crisis de valores y económica de los últimos años, encuentran en la educación universitaria, especialmente en las materias propias del derecho político y constitucional, en la paideia, una pieza fundamental para hacer real el compromiso de la universidad con la sociedad y con su tiempo, así como con las generaciones futuras.

Los avances científicos y tecnológicos si bien han desarrollado nuestro conocimiento sobre el medio, han relegado el estudio de las virtudes y defectos de la naturaleza humana que son los mismos en cualquier época y lugar, las llamadas ciencias del espíritu no pueden quedarse relegadas, especialmente el derecho que ha de despertar en las sociedades cuestiones y exigencias.

La relación educación/política se encuentra en las piedras angulares de Europa y hoy en el marco de Bolonia se plantea una necesidad ya antigua: debemos establecer los medios para formar políticamente a los ciudadanos. Recuperemos a Isócrates para enfrentarnos al reto de nuestros días en el Espacio Europeo de Educación Superior. Desde el derecho político solemos decir que la educación es política. Están en relación reflexiva el poder y el saber, de tal forma que uno nutre al otro y viceversa. Por ello abogamos una educación ética, que lejos de planteamientos sofistas y platónicos utilice herramientas eficaces y eficientes. Si la retórica en manos de Isócrates era entendida como un medio de acción política, las nuevas tecnologías de la información y de la comunicación, las TICS lo son ahora para el mismo objetivo.

Dando un salto de equibrista histórico también Ortega y Gasset, en su conocido ensayo Misión de la universidad, comentaba la necesidad de incorporar nuevas ideas y planteamientos para mejorar y modernizar la sociedad a través del espíritu crítico basado en el conocimiento, como función que la universidad debe asumir en su papel de participar activamente en el proceso de modernización de las sociedades avanzadas. En este panorama, a los responsables del área jurídica nos toca reflexionar sobre medios de superar y abordar desde planteamientos novedosos y más justos la convivencia humana en sociedad. Las aplicación de las nuevas tecnologías a las enseñanzas

5. Jaeger, W. Paideia: los ideales de la cultura griega. 2. ed. México: Fondo de Cultura Económica, 1978. p. 835. 
jurídicas de grado y postgrado desde la perspectiva de Bolonia facilitaran sensiblemente esta labor, pues además de mejorar la excelencia y la calidad de la formación teórico-práctica de los egresados en los estudios jurídicos, garantizan la igualdad mediante la utilización de herramientas de conocimiento de accesibilidad universal.

Nos enfrentamos, desde el ámbito jurídico, profesores y centros universitarios, a la tarea de formar ciudadanos capaces de conocer el sistema político/social en el que viven y se desarrollan, pues sólo el individuo que a través del conocimiento conoce la estructura, elementos y manifestaciones de las matrices del poder y la sociedad donde éste se manifiesta, es un ser humano libre, un ciudadano consciente de su realidad con capacidad para transformarla y mejorarla.

Así, nuestra primera propuesta es la incorporación de una materia que explicase a todos los universitarios en qué sistema político, social y económico viven y cuáles son las reglas de su participación en el mismo. Podría denominarse "derecho para el ciudadano". Ello cumpliría con los retos del Plan de Bolonia donde un Espacio Europeo de Educación Superior formará a los estudiantes como ciudadanos activos en una sociedad democrática. ${ }^{6} \mathrm{Su}$ docencia podría plantearse online lo que supondría cumplir con el reto de aplicar fórmulas eficaces propias de las nuevas tecnologías a la enseñanza del derecho para alcanzar, o al menos acercarnos a un sistema de democracia real ${ }^{7}$ donde los individuos que forman un Estado participen activamente en el mismo. Para ello han de ser conscientes de qué labor tienen ellos cómo base esencial y

6. Punto 1.5 del Comunicado de Londres Hacia el Espacio Europeo de Educación Superior: respondiendo a los retos de un mundo globalizado donde el 18.05.2007 se reunieron los Ministros responsables de la educación superior de los países que participan en el proceso de Bolonia, para verificar los progresos desde la reunión celebrada en Bergen en 2005. El punto 1.5 continua... la preparación de los estudiantes para su futuro profesional y capacitarles para su desarrollo personal; la creación y conservación de una extensa base de conocimiento avanzado; y el fomento de la investigación y la innovación. Sobre estos extremos se reflexiona en los siguientes epígrafes.

7. Hablamos de democracia real por entender que pese a los grandes avances que se han dado desde la expresión griega de este sistema político, la democracia representativa liberal expresada en numerosos textos constitucionales, a lo largo del Planeta, expresa desde nuestra perspectiva, una contradicción, quizás una paradoja jurídica en cuanto a su propia definición: la viabilidad económica del sistema democrático pretende con la lógica conservadora relegar el disenso y la participación al ámbito privado con la intención de lograr el consenso en la esfera pública. Paradójicamente se pretende un sistema democrático neutro y moral al mismo tiempo. De tal forma que bajo el parámetro de una tolerancia mal entendida, en el que todo vale, se manifiesta la intención maquiavélica de mantener y reproducir individuos apolíticos y no participativos. 
conformadora de la sociedad. ${ }^{8}$ Dentro de los retos de un mundo globalizado con exigencias de democracia real, abogamos por el derecho a un participación efectiva y responsable del pueblo en asuntos públicos, se pretende formar a los individuos en ciudadanos para dotarles de las capacidades de participación consciente y responsable en la gestión de la res pública, así como para crear y desarrollar actividades económicas y culturales productivas. La propuesta es hacer al individuo más responsable y con la intención de un acceso universal la metodología online cobra protagonismo. Lo mismo ocurre con la idea de un Parlamento virtual, que redimensiona el concepto de participación popular y el ejercicio de la soberanía del pueblo. Cuando entran en escena las nuevas tecnologías surge un mundo de nuevos conceptos y categorías donde caen las barreras para el ejercicio de la libertad de expresión y la igualdad se manifiesta por encima de cualquier tipo de diferencia.

La Profa. M. Rocasolano plantea con la paideia Isocrática ${ }^{9}$ una forma pacífica de superar situaciones de democracia "maquillada" a través de la educación en los valores democráticos y mediante los nuevos medios de comunicación social que la informática proporciona. Se cumple con la gobernanza, con la democracia y las exigencias de un mundo globalizado donde un alumno universitario tendrá las habilidades y conocerá las técnicas para exigir los mínimos que un Estado que se dice democrático debe cumplir. El siguiente paso es incorporar los mencionados conocimientos a todos, pues de otra manera la universitaria, sería nuevamente en la historia una élite social.

\section{LA APLICACIÓN DE LAS NUEVAS TECNOLOGÍAS A LAS ENSEÑANZAS JuRídicas de gRado y postgrado en el Marco del Plan de Bolonia}

Hoy la finalidad que guía el camino de superar la desigualdad y conseguir un verdadero sistema democrático, desde la reflexión profunda sobre la interpretación y contenido del derecho justo, pasa por la utilización de las

8. Así, podemos hablar de ciudadanos de primera o de segunda categoría (o individuos y ciudadanos) según tengan o no consciencia de su labor y sus funciones dentro del sistema social, sepan que pueden participar en la vida política y conozcan cómo se manifiesta el sistema económico de un país. Ya de antemano contesto a la objeción de que la ciudadanía no se puede limitar al conocimiento y que éste no puede ser un criterio diferenciador.

9. Para un mayor desarrollo de la idea de recuperar la Paideia véase Maria Méndez Rocasolano, Universidad, igualdad y democracia: la educación de ciudadanos frente al conocimiento de los individuos, revisión de la paideia Isocrática". Revista Leopoldianum, n. 83-84-85. 
nuevas tecnologías en las diversas facetas de la actividad docente en las enseñanzas jurídicas de grado y postgrado de los estudios jurídicos.

Si las tecnologías de la información y la comunicación han contribuido de forma sustancial a la construcción de las modernas sociedades postindustriales y a la creciente globalización económica y cultural, el campo del derecho no queda ajeno al envite de las nuevas tecnologías, manifestándose en la actualidad que la estrecha vinculación entre el derecho y las TIC es indiscutible. ${ }^{10}$ Así lo pone de manifiesto las profundas transformaciones que su incursión ha traído aparejadas, donde cabe mencionar en la relación TICS derecho, la emergencia de los llamados ciberdelitos, las complejas responsabilidades civiles y penales derivadas del uso de Internet, las nuevas fórmulas laborales como el teletrabajo, la contratación virtual y la utilización de la firma electrónica, entre otras muchas de las consecuencias jurídicas que conlleva el potente desarrollo de las TICS en un mundo globalizado.

Aquí, el derecho como instrumento del poder tiene un papel destacado. No debe olvidarse que el derecho está estructurado en la sistemática del poder y a la vez es estructurante, genera reglas de comportamiento y determina las instituciones precisas para el devenir de la sociedad. Así pues asumir un sistema democrático supone configurar un tipo de derecho en el que el poder se concibe por el pueblo, para el pueblo y con el pueblo. Se rompe entonces el juego del dominio y han de configurarse instrumentos normativos e institucionales que limiten la supremacía de las desigualdades. En este sentido, como indicábamos arriba es necesario una nueva politeia como expresión cultural que a través de la educación participe en la dimensión orgánica y estructural del sistema donde los fenómenos políticos superen lo burocrático y lo jurídicamente antidemocrático. Las nuevas tecnologías inculadas al derecho como hemos visto plantean nuevas formas de participación en la sociedad.

10. Al respecto es oportuno reflexionar, sobre la relación entre el derecho y la informática, en primer lugar debe diferenciarse la "informática jurídica" del "derecho informático o de las TIC", entendiendo que la primera expresión hace referencia a la herramienta electrónica al servicio del derecho para su desarrollo y aplicación, mientras que, la segunda hace alusión a la informática como objeto del derecho, es decir a la normativa reguladora de las nuevas tecnologías y a las relaciones jurídicas que surgen como consecuencia de las aplicaciones informáticas (Peñaranda, 2006). En concreto, esta rama del derecho especializada en las nuevas tecnologías ha conseguido tal pujanza que desde algunos sectores se plantea su estudio como derecho autónomo. En este mismo orden de cosas, es aconsejable que el alumno de grado y postgrado profundice en sus efectos más actuales, a la vez que es conveniente que realice un acercamiento a la regulación del sector informático y de las telecomunicaciones como complemento a su formación normativa y conceptual. 
Situados en el contexto educativo democrático, la aplicación de las TIC a la docencia y la formación teórico-práctica de los alumnos universitarios supone, sobre todo tras el impulso dado desde Bolonia, el fomento de modo transversal de la adquisición de competencias asociadas al manejo de las nuevas tecnologías de la información y de la comunicación como un medio de mejorar la excelencia y la calidad de los estudios universitarios. Especialmente, en la enseñanza del derecho se ha asumido el reto de formar a los futuros juristas en estas competencias, con efecto multiplicador como decía Isocrates, transformando a través de la interacción en la red a los educandos en educadores políticos de otros ciudadanos, que a su vez continuaran la labor emprendida. En la vertiente práctica, en el EEES se promueve la creación de espacios de debate y formación a la ciudadanía donde, explorando las nuevas posibilidades pedagógicas y didácticas que la incorporación de las nuevas tecnologías introduce, se despierta la conciencia política y participativa de los ciudadanos, haciéndoles conscientes de su necesaria participación, limitando el espacio existente entre la organización y los sectores en nombre de los cuales la organización se manifiesta. La expresión universal de la universidad se concreta entonces como una labor social educadora de ciudadanos, donde el poder se entiende como participación y participación de acceso universal.

A continuación, comentaremos cual es enfoque que desde Bolonia se ha dado a la adquisición de competencias ligadas a la utilización de las TIC y al carácter transversal que se propugna para ellas en la construcción del Espacio Europeo de Educación Superior, con el objetivo final de conseguir concretar propuestas factibles de aplicación de las nuevas tecnologías a las enseñanzas jurídicas, tanto de grado como de postgrado, que contribuyan a la excelencia y la calidad de la formación teórico-práctica de los alumnos, guiados por el propósito de una educación ética y política que actúe sobre las conciencias, y acepte los valores de igualdad, justicia, libertad y respeto por la dignidad de la persona en su vertiente individual y solidaria. Concretando, una pedagogía del poder a través de una metodología que despierte la iniciativa, el sentido crítico y la creatividad.

Como se ha dejado apuntado antes, una de las más beneficiosas aportaciones que se deriva de la aplicación de las nuevas tecnologías (fundamentalmente Internet) al ámbito de la enseñanza universitaria (y a la formación jurídica en particular) es que favorece el acceso universal de todo ciudadano a la educación superior, facilitando al alumno la incorporación al proceso educativo y el seguimiento del mismo en cualquiera de sus fases y campos de estudio, con independencia de sus circunstancias y disponibilidad (discapacidad, compromisos laborales o familiares, lejanía del centro docente, mayores etc.). Garantizar la implantación y mayor efectividad del principio de accesibilidad 
universal, supone a su vez aumentar las cotas de igualdad de todos los ciudadanos en el acceso a la enseñanza universitaria, por lo que los poderes públicos contemplan como una línea de actuación preferente todo lo relativo al fomento de este principio por vía de la utilización de nuevas tecnologías. En su desarrollo, en España se ha creado el Programa Campus de Excelencia Internacional con el objeto mejorar la calidad de las universidades españolas y conducir a la excelencia a los mejores campus en beneficio del conjunto de la sociedad, mediante la agregación, la especialización, la diferenciación y la internacionalización del sistema universitario español. En lo concreto, se ha establecido recientemente con la Fundación Europea para la Sociedad de la Información y la Administración Electrónica un acuerdo para desarrollar un programa de accesibilidad universal en el sistema universitario español cuyos objetivos se centran en "potenciar el desarrollo de los medios audiovisuales para asegurar la continuidad de la formación y difusión del conocimiento destinada a los estudiantes enfermos, desplazados o discapacitados, utilizando las tecnologías de la información y de la comunicación".

Así es como se manifiestan los avances en la docencia y la investigación de los estudios jurídicos, bajo la pretensión de un cambio en las estructuras de la conciencia social, donde siendo conscientes de la exigencia democrática se operará con la ayuda de las tecnologías de la información y de la comunicación una transformación cultural donde los ciudadanos, en un régimen de igualdad de oportunidades asuman la conciencia de su cuota de responsabilidad en la sociedad en la que viven.

\section{Propuestas concretas de Utilización de las nueVAs tecnologías EN LA DOCENCIA E INVESTIGACIÓN JURÍDICA EN EL ESPACIO EUROPEO DE EDUCACIÓN SUPERIOR}

En el desarrollo de la finalidad descrita líneas arriba, en España dentro del contexto del Plan de Bolonia, la Agencia Nacional para la Evaluación de la Calidad y Acreditación ha elaborado el Libro Blanco del Título de Grado en Derecho como modelo orientativo para la formulación de los nuevos planes de estudio. Entre diversas cuestiones, en este libro, se identifican las competencias transversales e instrumentales que los alumnos del grado en derecho han de adquirir para alcanzar una adecuada formación teórico-práctica que les permita el desarrollo y ejercicio cualificado de las distintas actividades profesionales a las que pueden acceder una vez se titulen (BArraycoA, J.; LASAGA, O., 2009).

Ciertamente la incursión de las TIC en el proceso educativo abre un nuevo horizonte de posibilidades en la docencia universitaria en general y en la 
enseñanza del derecho en particular, se "moderniza las aulas" y obliga a utilizar fórmulas innovadoras de enseñar y aprender derecho: "la utilización de las tecnologías de la información y la comunicación en todos los niveles de la enseñanza, en especial en el universitario, supone nuevos retos y oportunidades en los métodos y los procesos de aprendizaje. De ahí que estas tecnologías constituyan hoy día importantes instrumentos de docencia e investigación del derecho" (Delgado, Ana M. a.; Oliver, Rafael, 2003).

Los Profesores Pilar Conde Colmenero y Francisco de la Torre han reflexionado en este sentido sobre propuestas concretas que aplican las TICS a la enseñanza e investigación del derecho, tanto en grado como en postgrado. ${ }^{11}$ Sus ideas, sin duda contribuyen al desarrollo de la ciencia jurídica a través del planteamiento de líneas de estudio sobre las TIC que amplian los contenidos más tradicionales del derecho. En este sentido, destacamos la necesidad de formar al profesorado en la utilización de toda la batería de herramientas informáticas y electrónicas de las que pueden valerse en su labor docente e investigadora, así como la también necesidad de dotar de equipamientos informáticos para tal finalidad por parte de las instituciones universitarias. Ello exige un compromiso económico y la voluntad de introducir cambios tecnológicos en el modelo educativo que trasciende a las instituciones universitarias e implique a todos los actores del proceso educativo.

\section{Participación de la Administración Pública: el derecho en la red y el manejo de bases de datos jurídicas}

En el espacio virtual, las Administraciones Públicas de la mayoría de los países, han ido adquiriendo una presencia en la red cumpliendo con los objetivos de informar y acercar los servicios públicos al ciudadano mediante lo que se ha denominado administración electrónica. Es común la existencia de webs institucionales de organismos públicos que informan a los ciudadanos y a través de las cuales se puede cumplir con obligaciones administrativas que van desde

11. Al respecto recomendamos las lectura de La docencia del derecho y las TIC: iniciativas para la aplicación de las nuevas tecnologías a las enseñanzas jurídicas. Comunicación presentada al III Simposio Compostelano sobre Enseñanzas Jurídicas "Derecho en Bolonia”, organizado por la Universidad de Santiago de Compostela. Santiago de Compostela, 23 y 24.09.2010; e igualmente Propuestas para la aplicación de las nuevas tecnologías a las enseñanzas jurídicas de grado y postgrado desde la perspectiva de Bolonia, Comunicación presentada a la I Jornada sobre "Docencia del Derecho y tecnologías de la información y la comunicación”, organizada por la Universidad Oberta de Catalunya. Barcelona, 04.06.2010. 
el pago de impuestos y tributos, hasta la tramitación de solicitudes y recursos administrativos de toda índole. Así, en el ámbito de las relaciones del derecho público, nos encontramos como práctica habitual la intervención del jurista a través de la red para acceder a fuentes de información fiables de una manera ágil ${ }^{12}$ lo que hace que a partir de ese conocimiento del referente legal, jurisprudencial, administrativo y doctrinal puede actuar profesionalmente. Este imperativo de una praxis profesional por vía telemática, se explica desde la siguiente premisa: si el derecho es una herramienta de solución de problemas, haciendo valer los intereses dignos de tutela, su pronta satisfacción es una necesidad. Se cumple así por una parte la minimización de la burocracia que apuntaba Isocrates y el logro de procesos eficaces y eficientes reduciendo las dilaciones que ahorra la gestión telemática donde el término justicia tecnológicamente avanzada cobra sentido a través del libre acceso a las actividades de servicios y su ejercicio. Podemos decir que genera una nueva forma de relacionarse los administrados con la Administración (Palomar Olmeda, 2010).

En el ámbito del derecho privado, también se utiliza la administración y gestión telemática, por lo que la formación de los futuros juristas ha de incluir la instrucción en la actuación profesional vía telemática así como el entrenamiento en la utilización de bases de datos jurídicas que le permitan el acceso a fuentes normativas, jurisprudenciales y doctrinales actualizadas, la búsqueda informatizada de documentación especializada así como la resolución de supuestos prácticos. Para ello, desde estas líneas, se propone la inclusión en los Planes de Estudios del Grado en Derecho, de una asignatura específica que recoja estos contenidos y permita la adquisición de los conocimientos telemáticos descritos, ${ }^{13} \mathrm{su}$ denominación podría ser "informática y documentación jurídica" por ejemplo. Esta nueva materia, transversal, lograría una formación más técnica, sobre todo en el manejo de las herramientas de tratamientos de textos; y además aportaría a la formación jurídica general una visión interdisciplinar e integradora, con el conocimiento y uso de las bases de datos jurídicas.

12. La publicación del BOE a través de su página web evitando su impresión en papel es un ejemplo principal que ha sido emulado por los distintos boletines oficiales de las diversas comunidades autónomas y órganos legislativos supranacionales. Además con el valor añadido de posibilitar el recabar la certificación del documento que se precisa utilizar para un asunto profesional concreto.

13. Existen universidades que de forma innovadora ofrecen ya este tipo de asignatura en la planificación de sus estudios de derecho, como son la Universidad de Castilla-La Mancha o la Universidad Católica San Antonio de Murcia por citar dos ejemplos. 
En sentido similar se manifiesta esta necesidad en los estudios de postgrado jurídico, cuya finalidad es la especialización del alumno y su iniciación en el campo de la investigación. Aquí son aconsejables seminarios especializados donde se explique dentro de la metodología de la investigación jurídica la aplicación de las TIC a través del manejo electrónico de fuentes legales y bibliográficas incluidas en las bases de datos jurídicas, pues no se puede olvidar que en la actualidad, investigar en derecho pasa necesariamente por la utilización de los modernos métodos y herramientas que facilitan las tecnologías de la información y la documentación, y cuya utilización requiere un entrenamiento especializado que ha de suministrarse en esta fase de la enseñanza superior.

\section{Derecho online}

Comentábamos líneas arriba la posibilidad de cursar "online" o "en línea" contenidos que pertenecen al programa del grado de derecho y que deberían conocerse por parte de la sociedad, para lograr una participación activa, con la particularidad que aporta esta modalidad docente que garantiza el principio de accesibilidad universal.

Efectivamente, el seguimiento de los estudios jurídicos básicos mediante el sistema telemático facilita el acceso a aquellos alumnos que por determinadas circunstancias (lejanía, discapacidad, enfermedad, obligaciones familiares o profesionales, falta de disponibilidad...) podrían ver dificultado o incluso imposibilitado el desarrollo de la actividad universitaria en el campo jurídico. Aquí se manifiesta la "democratización de la enseñanza universitaria, ya que es posible el acceso a la formación universitaria para un mayor número de estudiantes y para más colectivos sociales, en igualdad de condiciones (Delgado, Ana M. a; Oliver, Rafael, 2003).

La ONU expresa una idea similar en el Texto aprobado por el Foro Mundial sobre la educación estableciendo que no puede admitirse que la calidad del aprendizaje y la adquisición de valores humanos y competencias disten tanto de las aspiraciones y necesidades de los individuos y las sociedades. -Comenta el texto-. Si no se avanza rápidamente hacia la educación para todos, no se lograrán los objetivos de reducción de la pobreza, adoptados en el plano nacional e internacional, y se acentuarán aún más las desigualdades entre países y dentro de una misma sociedad.

La inmediatez, agilidad, flexibilidad y actualización que se predican de la docencia online son sus principales ventajas, frente a otros sistemas de enseñanza más tradicionales, y representan algunas de las consecuencias más beneficiosas de la aplicación de las nuevas tecnologías a la docencia universitaria. 
En la actualidad el total de las universidades españolas incluyen en su oferta académica estudios de grado y postgrado que se pueden cursar íntegramente por vía telemática. Es más, el panorama universitario español cuenta ya con algunas instituciones dedicadas a la enseñanza superior que se han constituido ex profeso como plataformas virtuales donde el total de la docencia se plantea con carácter virtual y no presencial haciendo honor al principio de accesibilidad universal y abogando por la internacionalización de la educación superior. Es el caso de la Universidad Oberta de Cataluña (UOC) o la Universidad a Distancia de Madrid (Udima) que representan una apuesta decidida por la formación de calidad y flexible, a la vez que personalizada. Se trata de auténticas universidades online que para llevar a cabo su labor docente e investigadora recurren de manera novedosa a todas las posibilidades que ofrecen las nuevas tecnologías.

\section{Derecho en imágenes}

Considerando el derecho como herramienta útil por su utilización en la realidad material para hacerla realidad jurídica o para ajustarla al ordenamiento, parece conveniente formar a los futuros juristas en la habilidad o competencia de saber interpretar en clave jurídica toda fotografía, imagen o acotamiento de ese trozo de realidad. Con ese propósito formativo los profesores de la Torre y Conde proponen en un ejercicio de innovación y creatividad proyectar a los alumnos de grado en derecho imágenes del mundo exterior de modo que identifiquen y expliquen, desde categorías jurídicas, los conceptos, figuras o instituciones de derecho que concurran y la normativa ordenadora de dicha realidad.

Entienden que el jurista está llamado a esa visión de la realidad ajustada a derecho, comprendiendo cada supuesto de hecho, asumiendo el conflicto posible de intereses y aplicando la respuesta que permite ordenar o solucionar ese normal y pacífico devenir social.

Por otro lado, constituye esta nueva fórmula un aprendizaje ligado a la utilización de las TIC a través de la proyección, a los alumnos del Practicum, de los Masteres y del Postgrado, de grabaciones audiovisuales que reproduzcan las actuaciones judiciales más frecuentes de los distintos órdenes jurisdiccionales (juicios, vistas y demás actuaciones ante los juzgados y tribunales). Con la escenificación por video en el aula de la realidad forense, buscando su análisis e interpretación jurídica, se prepara al estudiante para un ejercicio profesional (de la judicatura, la abogacía, la procuraduría o la fiscalía) que pasa por la intervención "en estrados". Se contribuye a una formación práctica más rica y cercana a la realidad de la actividad judicial y, a su vez, se consigue que el alumno obtenga una imagen fiel del desarrollo del proceso judicial, de la puesta en práctica de las estrategias de defensa y acusación y, en definitiva, del funcionamiento de la administración de Justicia. 


\section{Conclusiones}

Una mirada a las sociedades de los países europeos aporta una visión del poder en sentido sistémico donde observamos cómo se configuran los tipos de Estados sobre las potencias vitales de unos individuos, que ordena y disciplina a través de normas e instituciones con pretensiones democráticas. Desde la antigua Grecia la cultura se vincula al sistema de poder, que la utiliza estableciendo valores que a él le interesan a través de instituciones históricas y esenciales como la familia, los centros educativos, los medios de comunicación, las instituciones básicas de organización etc. Es decir, la cultura opera como una matriz generadora de comportamientos, valores, costumbres, códigos de lenguajes, actitudes, hábitos y relaciones sociales en la que se reproducen las relaciones de dominación-dependencia vigentes en la sociedad. Desde un Espacio Común de Educación Superior en Europa y por ende en España, se plantea el examen de la relación entre la estructura del poder y la cultura pues la pretensión de las instituciones comunitarias en el plan de Bolonia es que las universidades sean centros de promoción y afianzamiento de las cohesión social y de reducción de desigualdades, para lo que el derecho es protagonista indudable. Con el planteamiento de una educación ética, a través de un ideal pedagógico que pretende una democracia sustentada por las virtudes de la justicia y la equidad hablamos de un sistema educativo fundado en valores cuya expresión puede reducirse al respeto por la dignidad de la persona y los derechos humanos. Con una asignatura que podría denominarse derecho para la ciudadanía se pretende introducir cambios en las reglas de poder/saber que constituyan formas de respeto por la dignidad de la persona como homo civitatis. Si el saber y el poder no pueden separarse, se requiere conocer las relaciones de lucha y de poder, las de dominación de unos hombres sobre otros, para comprender la producción de conocimiento, y la estructuras políticas y las condiciones de existencia en el aparato sociopolítico. ${ }^{14}$ Esta nueva asignatura hace que el derecho se permeabilice en la estructura social, saliendo del coto universitario para formar a los ciudadanos en sus derechos y obligaciones. En sentido similar proponemos el desarrollo de un Parlamento virtual donde se facilite la participación del pueblo en el desarrollo de sus funciones soberanas. Para ambas, las nuevas tecnologías son imprescindibles. Las TICS al servicio del derecho, como a su

14. Para un estudio más detenido respecto de las relaciones de poder y la cultura , especialmente en relación con los derechos humanos recomendamos la lectura de la parte I: A dialética de poder e os direitos humanos :da negaçâo a reinvindicaçâo, p. 21101 en Oliveira da Silveira, V.; Rocasolano, M. Direitos humanos, conceitos, significados e funçoes. São Paulo: Saraiva, 2010. 
enseñanza representan una tendencia innovadora y coherente con los valores y principios propios de un sistema democrático, procuran la participación real en los asuntos públicos, garantizan el ejercicio efectivo del derecho a la igualdad y no discriminación a partir del principio de accesibilidad universal.

Las universidades y así también sus facultades de derecho tienen que evolucionar para ser verdaderos centros de las TIC como lógica sede a la que se incorporará en un futuro inmediato el alumnado proveniente de las llamadas "escuelas TIC" que hoy ya son una realidad en el sistema educativo actual. Se pretende una educación ciudadana, que a través de las innovadores y diversas redes de comunicación y organización consigan verdaderos ciudadanos a través de la educación en valores. La educación es un derecho humano fundamental, y como tal es un elemento clave del desarrollo, de la paz, de la convivencia pacífica y la estabilidad económica e institucional de cada país y entre las naciones. Podemos considerarla como dice la ONU como medio indispensable para participar en los sistemas sociales y económicos del siglo XXI. Esta cultura social acerca a la población como indicaba Isócrates al Estado, el pueblo siente suya y se compromete en la estructura de poder y quizás esta sea una de las vías para desterrar abusos y desigualdades.

La aplicación de las nuevas tecnologías a las enseñanzas jurídicas de grado y postgrado. contribuye a la construcción de un moderno sistema universitario congruente con las exigencias y expectativas que plantea el Espacio Europeo de Enseñanza Superior y el proceso de Bolonia. En este marco es necesario la adquisición, en cada campo de estudio, de competencias de carácter transversal e instrumental conectadas con la utilización de las nuevas tecnologías ligadas a los perfiles profesionales propios de cada disciplina o área de conocimiento. Particularmente la práctica del derecho está estrechamente vinculada con los avances tecnológicos, lo que pone de manifiesto lo importante que es instruir a los futuros juristas en estas cuestiones utilizando las más innovadoras técnicas y herramientas docentes del mundo de las nuevas tecnologías.

La universidad al desarrollar las propuestas contenidas en este trabajo en cuanto a expresiones concretas, como el derecho en la red y el manejo de bases de datos jurídicas, el derecho online y el derecho en imágenes contribuye a la generación de propuestas sostenibles, eficaces y eficientes que representa la internacionalización de una universidad con menores costes ágil e inmediata. Además sirve de plataforma para la difusión, a toda la comunidad universitaria, del derecho de la nuevas tecnologías, aprovechando que, al formar a los juristas mediante estos medios y nuevos cauces, se evoluciona desde la informática jurídica a favor del derecho de las TICS, pudiéndose abrir así líneas de investigación en esta novedosa materia e impartiéndose una docencia especializada que han de servir a la sociedad. 
En definitiva, los profesores, alumnos e instituciones, la comunidad académica de los estudios jurídicos de Grado y de Postgrado debemos con la cohesión social y la participación de una ciudadanía responsable en el horizonte, aplicar las nuevas tecnologías de la comunicación y la información a la enseñanza y a la investigación universitaria del derecho, pues estas representan el mejor medio para atender a la cuestión que supone la expansión y universalización de la formación universitaria que además se presta en igualdad de condiciones.

\section{BibLIOGRAFía}

Agencia Nacional para la Evaluación de la Calidad y Acreditación. Libro Blanco del Título de Grado en Derecho, 2006.

Barraycoa Martínez, J.; Lasaga Millet, O. La importancia de las competencias instrumentales en la empleabilidad: el caso de los conocimientos informáticos. 2009. Disponible: [www.uao.es] (artículo en línea).

Bowen, J. Historia de la educación occidental. Barcelona: Herder, 1976. vol. 1.

BurCKHARDT, J. Historia de la cultura griega. Barcelona: Iberia, 1964. vol. 1.

Cohen, R. Historia de Grecia. 3. ed. Barcelona: Surco, 1962.

Cortina, a. Ciudadanos del mundo. Hacia una teoría de la ciudadanía. Madrid: Alianza Editorial, 1997.

De la Torre Olid, F; Conde colmenero, P. La docencia del derecho y las TIC: iniciativas para la aplicación de las nuevas tecnologías a las enseñanzas jurídicas. Comunicación presentada al III Simposio Compostelano sobre Enseñanzas Jurídicas Derecho en Bolonia, organizado por la Universidad de Santiago de Compostela. Santiago de Compostela, 23 y 24.09.2010.

Propuestas para la aplicación de las nuevas tecnologías a las enseñanzas jurídicas de grado y postgrado desde la perspectiva de Bolonia. Comunicación presentada a la I Jornada sobre "Docencia del Derecho y tecnologías de la información y la comunicación”, organizada por la Universidad Oberta de Catalunya. Barcelona, 04.06.2010.

Delgado, Ana M. ${ }^{\text {a; }}$ Oliver, Rafael. Enseñanza del derecho y tecnologías de la información y la comunicación. 2003. (artículo en línea) UOC (Fecha de consulta: 20.01.2010)

Elejalde, A. F. Educación y política. Lima, 1995.

Fraboschi, A.; Stramiello, C.; Sánchez, M.; García, C. Isócrates: la formación ética del hombre político (el gobernante y el ciudadano). Buenos Aires: Instituto de Estudios Grecolatinos/Prof. F. Nóvoa, 1995.

Galino, M. A. Historia de la educación. 2. ed. Madrid: Gredos, 1968. t. 1.

Isócrates. Discours. Paris: Les Belles Lettres, 1928-1972. t. 4.

Oraciones políticas y forenses de Isócrates. Trad. A. Ranz Romanillos. Madrid: Librería de la Vda de Hernando y Cia, 1981. vol. 2. 
Speeches and Letters (ed. George Norlin). Cambridge/London: Harvard University Press/William Heinemann Ltd., 1980.

Jaeger, W. Paideia: los ideales de la cultura griega. 2. ed. México: Fondo de Cultura Económica, 1978.

Jouguet, P. El imperialismo macedónico y la helenización del Oriente. Barcelona: Cervantes, 1927.

Martinez, M. El contrato moral del profesorado. Condiciones para una nueva escuela. 3. ed. Bilbao: Desclée de Brouwer, 2001.

Oliveira da Silveira, V.; Rocasolano, M. Direitos humanos, conceitos, significados e funções. São Paulo: Saraiva, 2010.

Palomar Olmeda, Alberto. Directiva de servicios y administración electrónica: dos nuevos retos para las Administraciones Públicas y un cambio profundo en su régimen de actuación. Actualidad Jurídica. n. 798. 2010.

Peñaranda Quintero, Héctor Ramón. La informática jurídica y el derecho informático como ciencias. 2006. Disponible: [www.monografías.com] (artículo en línea).

Rawls, J. Liberalismo político. Barcelona: Crítica, 1996.

Rebellato, J. L. Algunas reflexiones sobre educación popular, sociedad civil, autonomía popular. En: Grossi. Francisco Vio (ed.). Educación popular, sociedad civil y desarrollo alternativo. Santiago de Chile: Aconcagua-CEAAL, 1998. p. 103-114.

Rocasolano, M. Universidad, igualdad y democracia: la educación de ciudadanos frente al conocimiento de los individuos, revisión de la paideia Isocrática. Revista Leopoldianum. n. 83-84-85. Santos: Universitaria Leopoldianum, 2003.

TAYLOR, C. La ética de la autenticidad. Barcelona: Paidós, 1994.

ThIEBAut, C. Los límites de la comunidad: las críticas comunitaristas y neoaristotélicas al programa moderno. Madrid: Centro de Estudios Constitucionales, 1992.

VV.AA. Relaciones laborales y nuevas tecnologías. Madrid: La Ley, 2005.

\section{Pesouisas do Editorial}

\section{Veja também Doutrina}

- 0 direito constitucional à educação superior de qualidade uma análise reflexiva entre os objetivos propostos pelo sistema nacional de avaliação da educação superior - Sinaes (Brasil) e as diretrizes previstas na Declaração de Bolonha da União Europeia, de Adalberto Simão Filho, Lucas de Souza Lehfeld e Neide Aparecida de Souza Lehfeld - RDCl 74/131. 